総

説

\title{
ハイブリッド車の動向と磁性材料への期待
}

\author{
久保馨 \\ トヨタ自動車(侏)HVユニット開発部，テ 471-8571 豊田市トヨ夕町 1 番地.
}

\section{Trend of the Hybrid Vehicle and Expectation to the Magnetic Materials}

\author{
Kaoru Kubo \\ Toyota Motor Corporation Hybrid Vehicle Unit Development Division, 1 Toyota-cho, Toyota 471-8571.
}

Received November 29, 2004

\section{SYNOPSIS}

Environmental issues are greatly affected by the automobiles. One of the solutions is to introduce Green Cars into the market. Currently, Hybrid vehicles are green cars with good environmental performance and are expected to be popularized.HVs should have motor, inverter and batteries in addition to the conventional ICE vehicle units. Therefore, being compact, light-weighted and low cost are highly required.

Specific output of PM in current HVs has improved about 3.5 times more than a DC motor in early EV.

As of motor size, if $700 \mathrm{MGOe}$ from MEXT's* prospect will be implemented, it is possible to reduce the motor size by 30 to $40 \%$ with only material change.

It is quite safe to say that HVs' revolution with overwhelming fuel economy, environmental performance and quietness is achieved by materials improvement of units such as motor.

${ }^{*}$ Ministry of Education, Culture, Sports, Science and Technology

KEYWORDS

Hybrid Vehicle, Efficiency, Magnetic Material, Permanent Magnetic Motor

\section{1 緒 言}

21 世紀は「環境の世紀」と言われ，20世紀の負の遺産であ る地球環境問題, 都市環境問題, エネルギ一問題の早期解決 が期待されている.自動車業界が今後永続的発展を遂げるた めにはこれらの問題を解決することが責務である.

現在日米欧の政府により従来基準に対し非常に厳しい排気 規制や燃費規制が検討されている ${ }^{1)}$ (Fig.1).

米国では2005年よりカリフォルニア州で販売台数の10\%を ZEV(Zero Emission Vehicle) に義務付けする規制がはじまる.

欧州ではステップIVの排気規制と2009年から $\mathrm{CO}_{2} 140 \mathrm{~g} / \mathrm{km}$ の自主規制がはじまる。

日本でも2005年から新長期排気規制がはじまる.これらの 規制対応には従来の改良レベルでは到底達することが出来な い基準もあり，各自動車メ一力は開発に力を注いでいる. 対 応の現実的解の一つとしてハイフリッド車 (以下HV)の導入 がある. 本論文ではこの HVの主要ユニットであるモー夕の 概要と構成部品の材料である磁性体への期待について述べる.

\section{2 何故ハイブリッド車か}

各種動力源のWell To Wheel(原油精製から車両走行まで)の $\mathrm{CO}_{2}$ 排出量 (败料消費)を Fig.2に示す. ガソリン自動車の $\mathrm{CO}_{2}$ 排出量を 1 とすると，ハイブリッド車は半分しかなく，究極 のエコカーといわれる FCHVと比較しても遜色かなく極めて 優れているといえる. 何故 $\mathrm{HV}$ は $\mathrm{CO}_{2}$ 排出量が少ないか，言 い換えれば何故効率が良いかの理由を以下に述べる.

一例としてFig.3にトヨタプリウスに搭載しているトヨタハ イブリッドシステムII の動作モードで HV の走行時における エネルギー収支を示す。図中太線で示した線が走行に必要な エネルギーであり，エンジン出力を破線で示す．

車両停止時やエンジン効率の悪い動作点ではエンジンを積 極的に停止し無䭾な燃料を消費しない，走行中はエンジンが 最高効率になるように制御し，電池充電量不足時には余剩工 ネルギーを電池に蓄える。制動時，通常のクルマは運動エネ ルギーをブレーキで熱エネルギーに変えて空中に放出してい るが, HVは駆動用モー夕を発電機として利用し, 減速時の運 


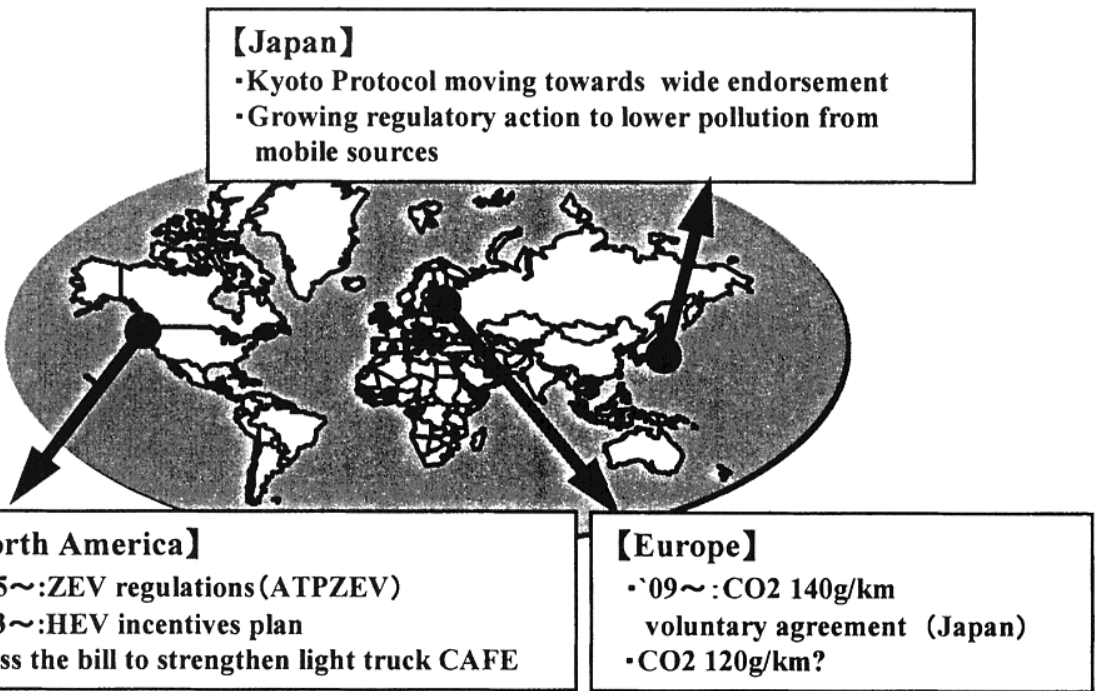

Fig.1 The conditions surrounding HVs.

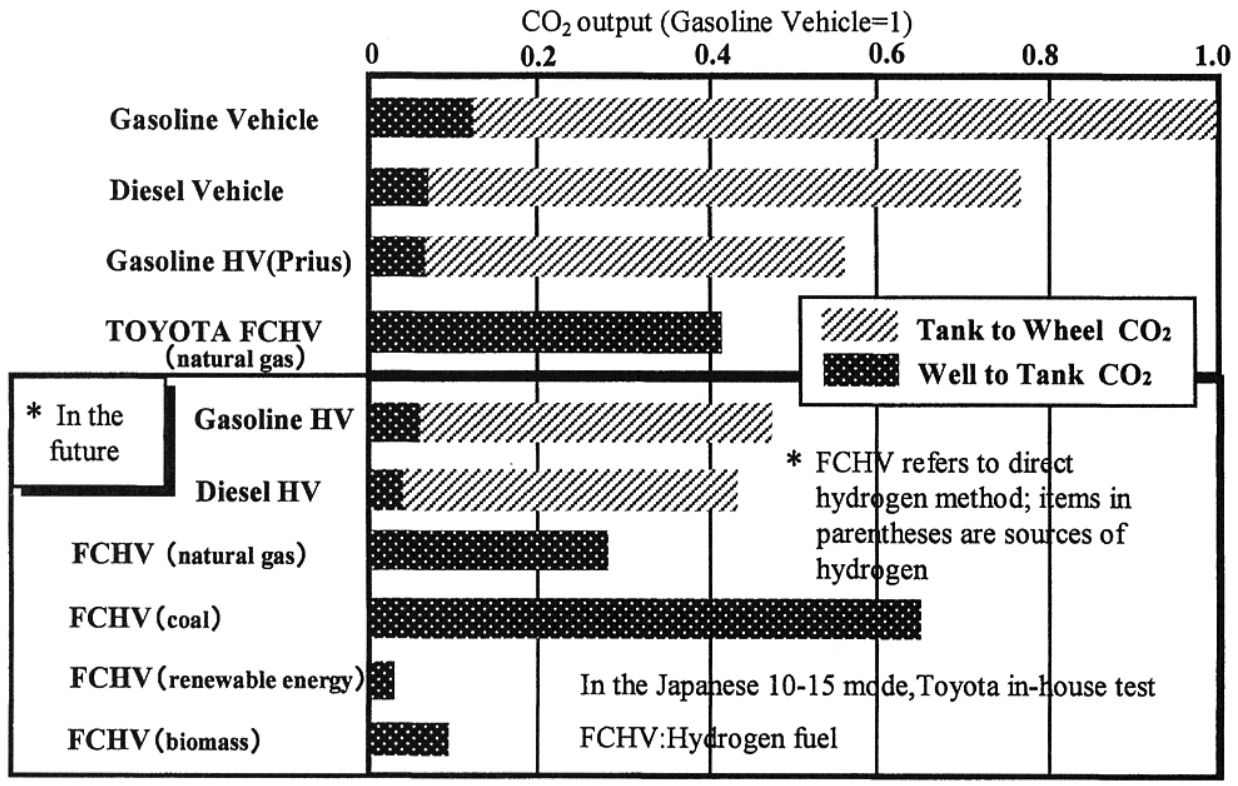

Fig.2 Well to Wheel $\mathrm{CO}_{2}$ emissions.

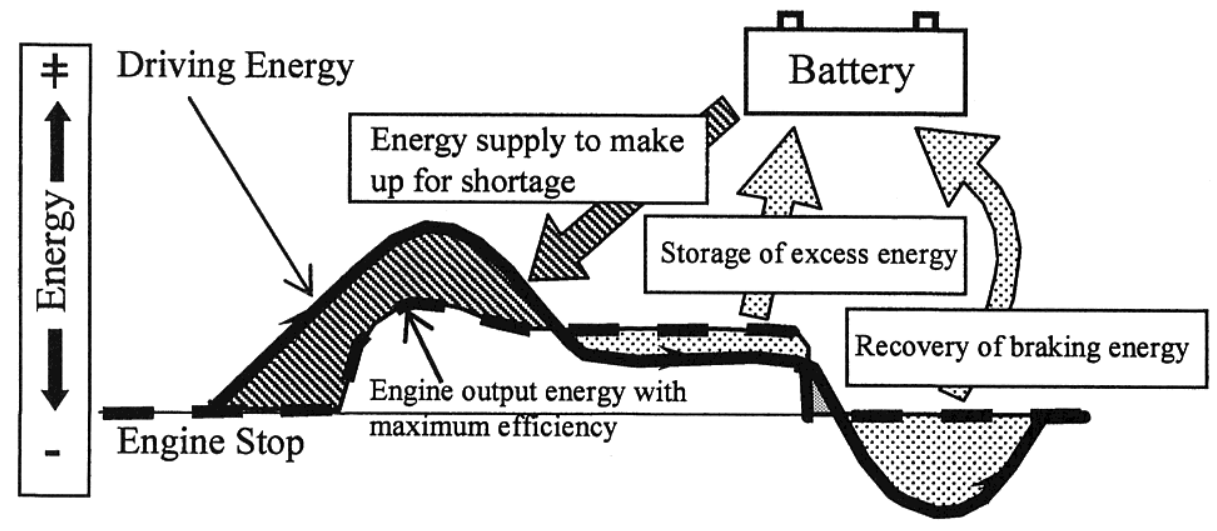

Fig.3 Reason why HV is efficient. 
動エネルギーを電気エネルギーに変え, 電力として電池に蓄 えている.このようにきめ細かいエネルギー管理をすること により, HVは従来のガソリン車に比べ効率 (燃費)を改善す ることが可能である.

ハイブリッドシステムには動力伝達構造の面から, シリー ズとパラレルに分類される.また機能の面からトヨタではマ イルド HV とストロング HVに分類している (Fig.4).

マイルド HVは車両停止時のエンジンアイドリング回転停 止,加速時に必要な追加動力をモータが補うモータアシスト, 減速時の運動エネルギーを，モータを発電機として利用して 電気エネルギーに変換し電池に戻す時に生じる回生ブレーキ を備えている.さらにEV走行を可能としたシステムをストロ ングHVと定義している. マイルドHVからストロングHVに なると燃費の向上, EV 走行による静肃性等機能は充実する が, 反面コスト低減の課題も大きくなり, 今後の動向が注目 される.
HVでは限られた搭載スペースの中で従来の内燃機関に加え て Fig.5に示すようにモータ,インバー夕, 電池などの体積の ある専用部品を搭載しなければならないため, 各コンポーネ ントの小型軽量化が強く要求される. 加えて, 普及のために は低コスト化が重要な課題であることは言うまでもない.

\section{3 磁性材料への期待}

\section{1 磁石への期待}

Fig.6に東京モーターショーで発表された駆動モー夕形式の 推移を示すが, 過去に多かった直流モ一夕や誘導モ一夕に対 し，近年では永久磁石モー夕が採用される例が多くなってき ている.

これは高性能な希土類永久磁石が高温特性等の性能向上だ けでなくコスト面でも自動車用途として利用可能になったか らであり,これにより飛躍的なモー夕の出力密度の向上が可 能になってきた。

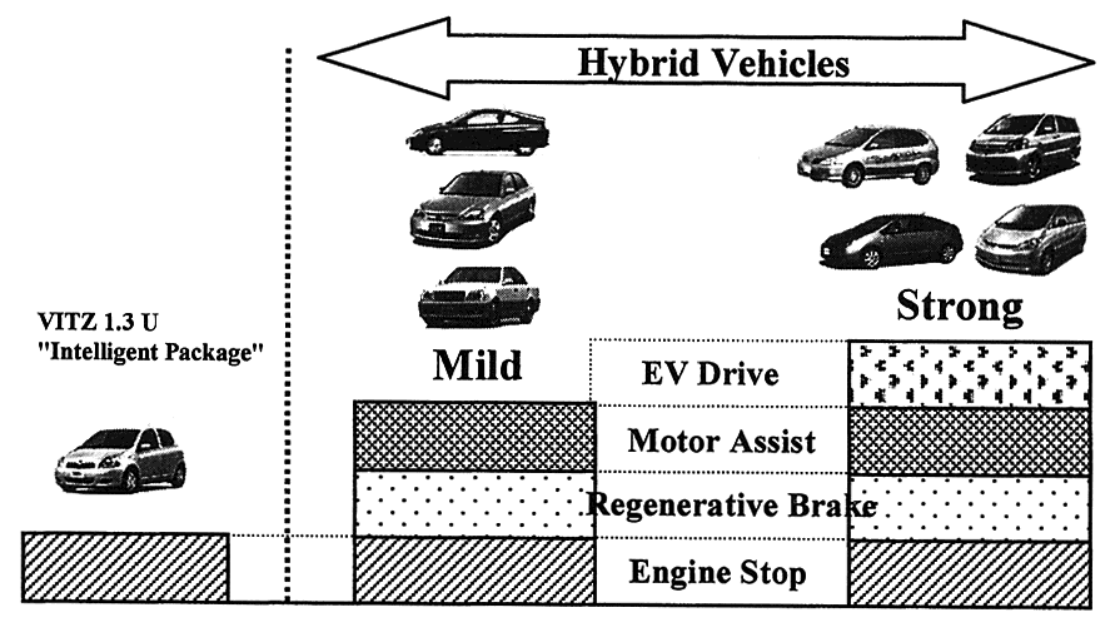

Fig.4 Hybrid Functional Category.

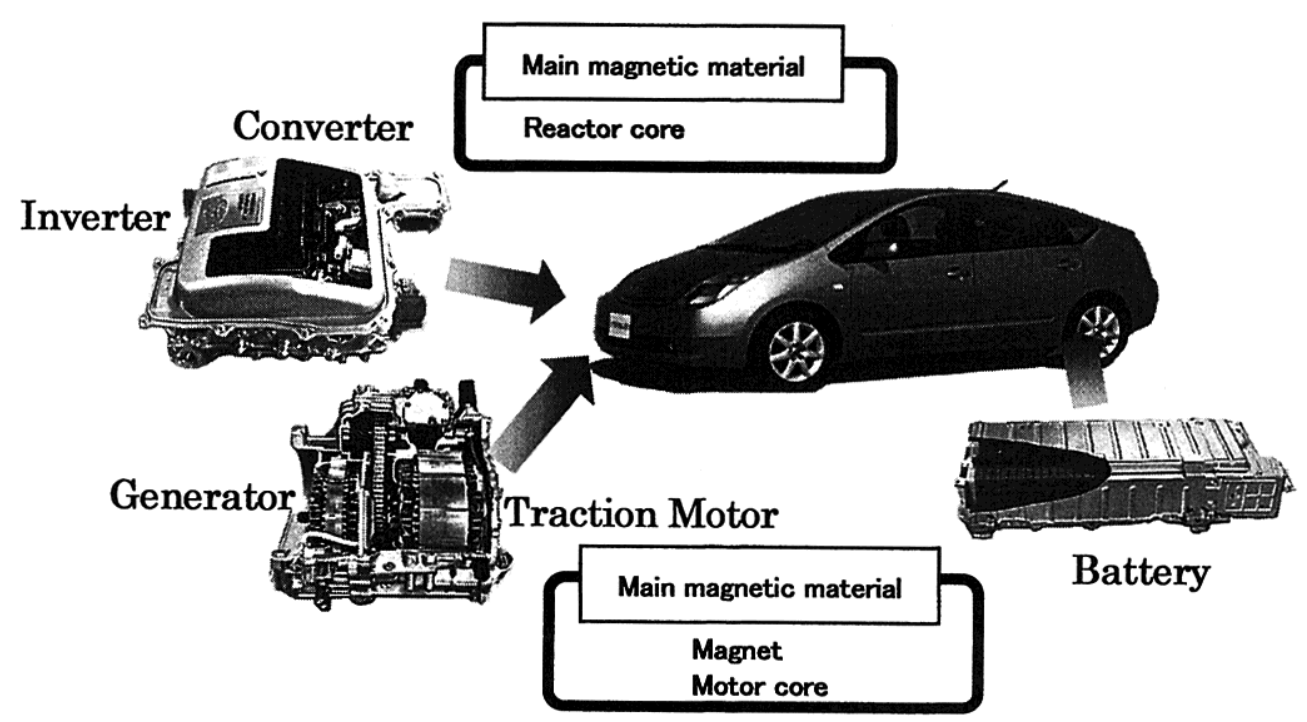

Fig.5 Special units to HVs. 


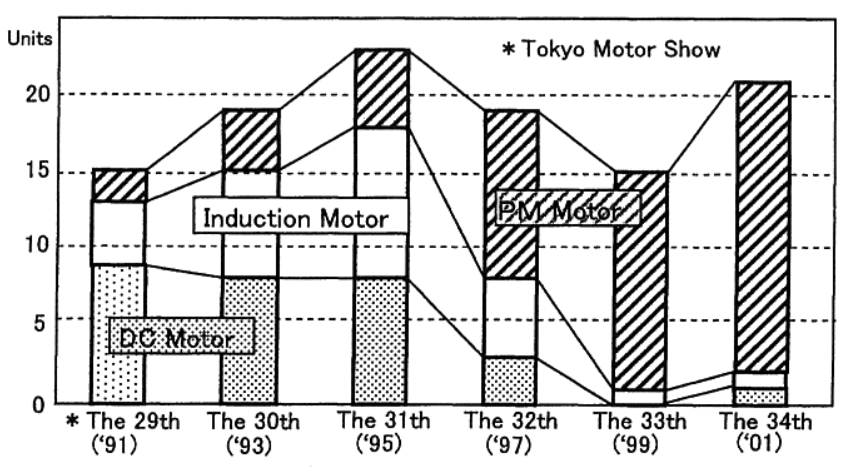

Fig.6 Trend of Traction Motor for EV/HV.

Fig.7 に例としてトヨタでのモータ出力密度の推移を示す. '03年モデルのプリウスでは初期のEV-10で採用した直流モ一 夕に比べ約 3.5 倍の出力密度を達成している.

3.2 モータコア材料への期待

もう一つの強い要求が損失低減である.乗用車用途の場合, 特に使用頻度の多い市街地走行は, 車両駆動用モー夕では軽 負荷域の使用頻度が高いことが特徵となる(Fig.8). 現在, モ一 タコア材料として電磁鋼板を用いているが, Fig.9に示すモ一 夕の損失特性からわかるように, 軽負荷領域での鉄損の占め る割合が大きく，さらなる燃費向上を図るために鉄損を低減 する強い要求がある. 一方, 圧粉磁心も性能の向上など新た なコア材料として注目されてきている.また，圧粉磁心はそ の高周波特性の良さからリアクトル用コア材料としての可能 性も高いものと思われる.

先述の永久磁石を初め, モ一タやその他部品に使用されて いる磁性材料の高性能化は HV 技術革新のキ一技術の一つで ある. 低コスト化もあわせてこの分野での新しい提案を期待 したい.

\section{3 磁性材料の性能向上による効果}

科学技術庁 (現文部科学省)の「第 5 回技術予測調査」によ れば,

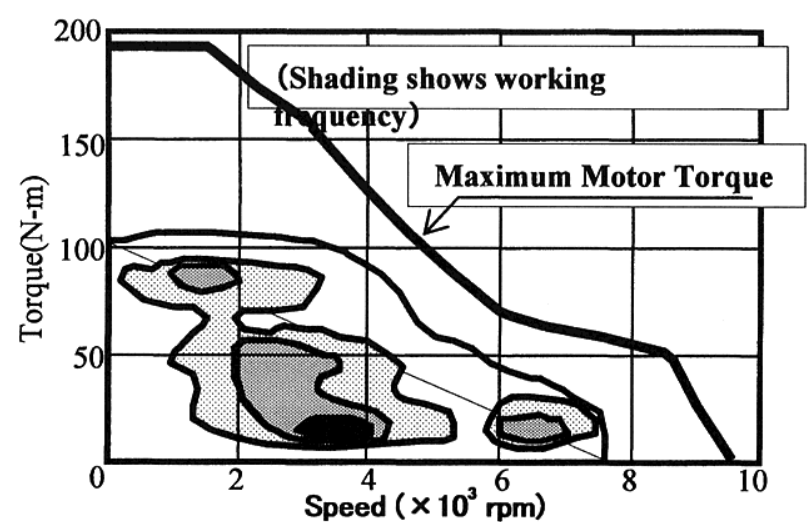

Fig.8 Frequency Map in Urban Drive condition.

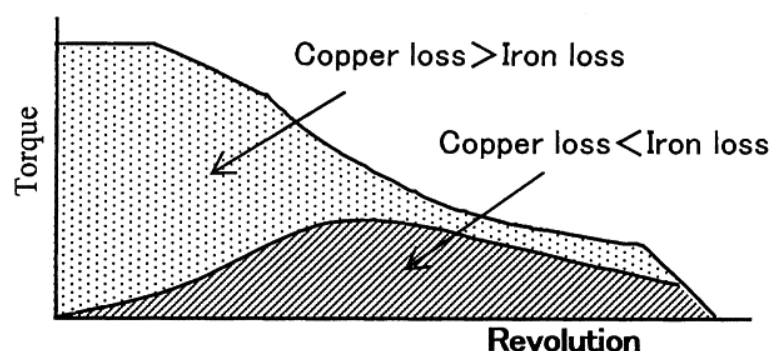

Fig.9 Characteristics of Motor Loss.

2002 年: BHmaxが70MGOeを超える永久磁石材料が開発 2003 年: 飽和磁化 $3 \mathrm{~T}$ 以上のバルク磁性材料が開発 という予測があった。

この予測が実現していれば，材料変更だけで現状のモー夕 体格を30〜 40\%の低減が可能という大きな効果が得られるこ とになる。

このように磁性材料のブレークスルーは磁性材料の適用に 大きな変化をもたらすことから今後，この分野の新しい提案 を期待したい (Fig.10).

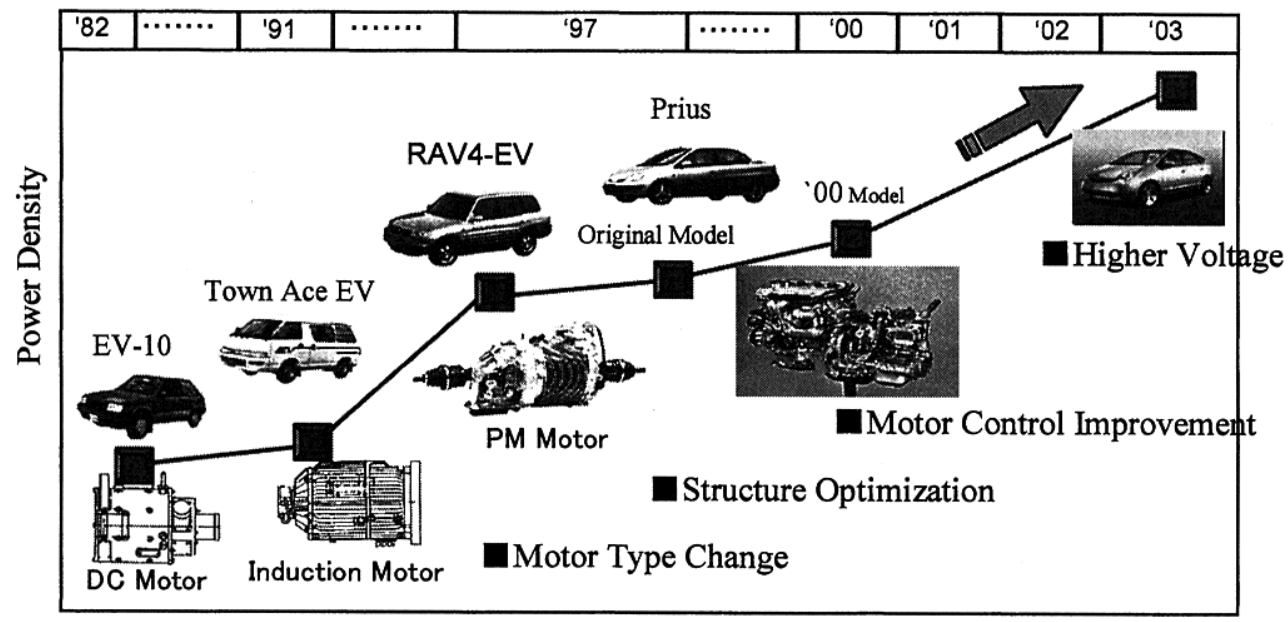

Fig.7 Transition of Motor Power Density in Toyota. 
Permanent Magnet with BHmax $=$ 70MGOe
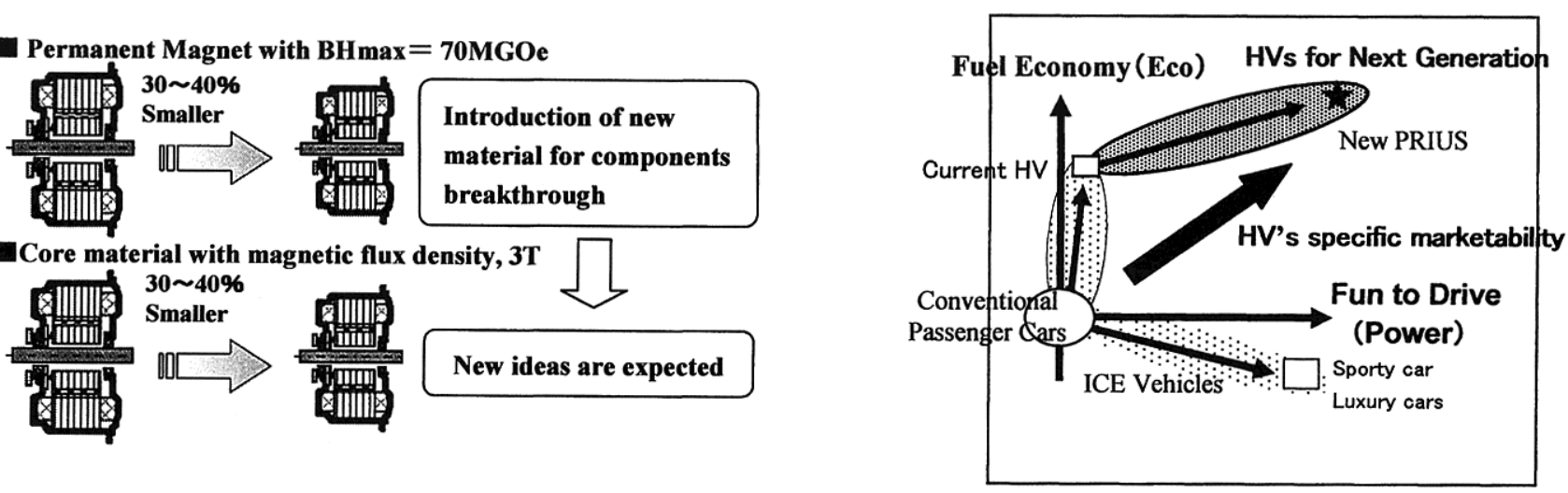

Fig.10 Effect in Traction Motor.

Fig.11 Evolution of HVs.

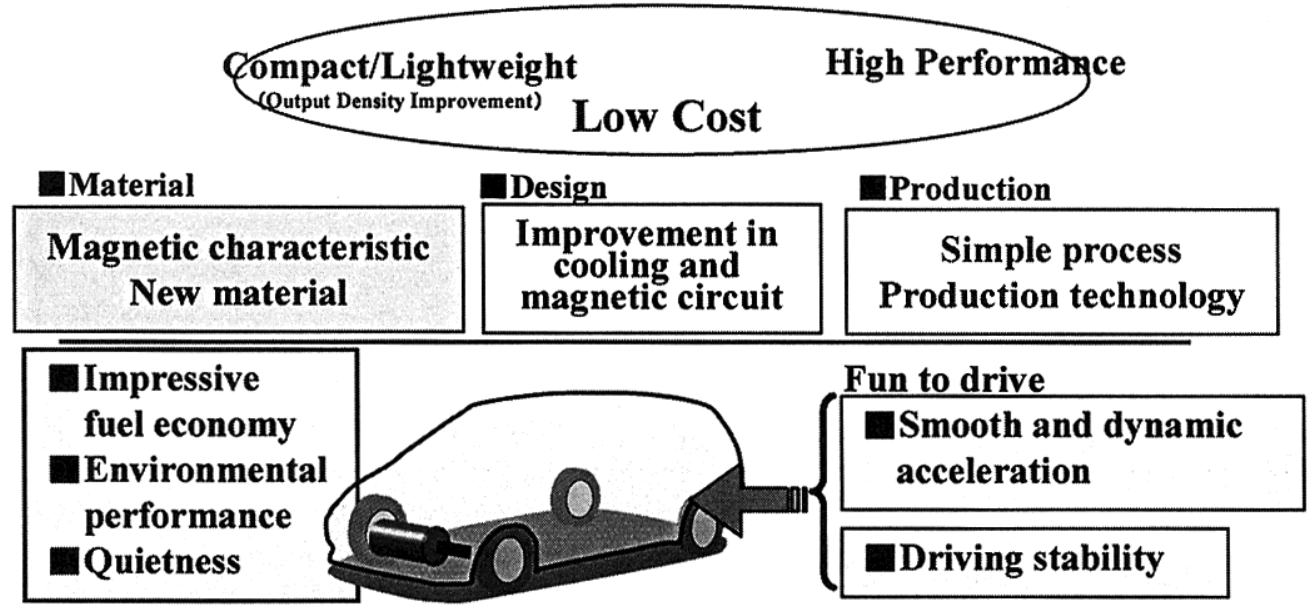

Fig.12 Task and Prospect in the future.

4 将来の HVの方向性

トヨタは, 従来のトヨタハイブリッドシステム (THS) を進 化させたTHS II を搭載した新型プリウスを 2003 年9月に発売 した. 燃費志向であった従来のシステムに対し, 燃費 (エコ) と走り(パワー)を両立させたシステムであり次世代の HVの 進む方向ともいえる (Fig.11).

\section{5 課題と今後の展望}

先に述べたようにハイブリッド車は従来のガソリン車に新 たにモータ, インバータ, 電池の搭載が必要になる. HVの本 格的普及に向け, ユニットレベルでは小型化と低コスト化に
取り組み，更なる技術革新が必要になる.

車両側でも圧倒的な燃費向上, 環境性能, 静肃性に加えFun to drive な走りの向上にむけて開発を進めていく必要がある (Fig.12).

将来のクルマ即ち HVの進化を材料の革新が支えていると いっても過言ではないであろう.

\section{文献}

1) California Zero Emission Vehicle Regulation established by CARB (2003), 2005-2007 MY Truck CAFÉ Rule established by NHTSA (2003) and others. 